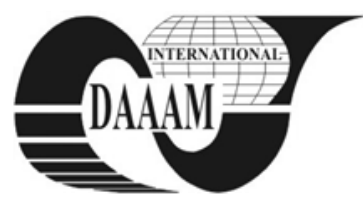

Annals of DAAAM for 2011 \& Proceedings of the 22nd International DAAAM Symposium, Volume 22, No. 1, ISSN 1726-9679 ISBN 978-3-901509-83-4, Editor B. Katalinic, Published by DAAAM International, Vienna, Austria, EU, 2011 Make Harmony between Technology and Nature, and Your Mind will Fly Free as a Bird

\title{
BUSINESS STRATEGIES REGARDING THE EVALUATION OF LEADERSHIP STYLES
}

\author{
CHERECHES, C[atalin]; TOADER, R[ita]; RADULESCU, C[orina] M[ichaella]; \\ ZIMA, L[iliana] A[dela] \& SABOU, S[imona]
}

\begin{abstract}
This paper presents factors that influence leadership, the effects of leadership styles, leadership interpersonal and organizational, leadership symbiotic, transformational.

In the pape rit is described a mathematical model of leadership style assessment

Key words: leadership, evaluation, human resources, performance
\end{abstract}

\section{INTRODUCTION}

Leadership is an important component of human resource management and integrating role among various components of human resource management first and most important stage in the development of leadership is the selection of leaders, because when chosen the wrong person, trying to develop has little effect.

Leadership is an essential variable leads to an improved ability to lead and organizational performance. describes the hypothetical relationship between leadership and organizational performance. With time a certain organizational culture, how leadership is exercised largely determines the capacity of management. But increased management capacity does not necessarily lead to higher organizational performance.

To achieve this, the leadership of the leaders is very important to achieve the proposed performance. Culture performed this process directly or indirectly, sometimes as an accelerator, sometimes as an obstacle. Thus, leadership is very important to obtain an enhanced management and organizational performance.

This results-oriented context, the organization usually provides a degree of freedom and flexibility to contribute to results. Leaders must be able to use this flexibility to motivate subordinates and to offer them the necessary boost to achieve its mission. Leaders inspire people of quality. Changing organizations is actually changing people's behavior. Leaders, located throughout the organization can contribute to the dissemination and maintenance of new values, necessary for the success of the organization.

\section{FACTORS INFLUENCING LEADERSHIP}

Content, expression and leadership effectiveness are just some of the major factors of leadership, of which three are considered to be determined, namely:

-native characteristics of the person or leader;

-leadership training received;

- situation the leader is or is placed.

The main characteristics of leaders are:

a) physical - leadership requires a lot of work, which can be inferred that the leader must possess outstanding energyş

b) detemination- leader must have goals and lead others to adopt

c) enthusiasm - the leader must be competent to be recognized as the authority d) generosity and human warmth - the leader should not be afraid to be loved, but loved inlays to be followed by others, a) integrity - leaders must be trustworthy.

Precise definition of objectives to be achieved through leadership:

-the transmission of sensitive information, knowledge, attraction, persuasion, inspiration, drive to subordinates within sessions and individual meetings;

-scheduling tasks to subordinates according to the leader and leadership goals;

-calling method common in the delegation of tasks, powers and authority - mentor, is a specific technique, outlined in recent decades in developed countries where managers promote leadership.

In essence, the mentor is conducting regular meetings between managers and subordinates, individually, in which, in a relaxed and open discusses the potential and its evolution in terms of professional opportunities. Negotiating with informal leaders (leaders enjoying the appreciation and the component group, due to their conviction of the high value of the leader).

Value resulting from the authority of specialized knowledge and skills possessed by him and management, this position is acquired over time as opposed to formal leaders whose authority is obtained immediately with job assignment in order to obtain intense participation in the exercise of leadership;

\section{TYPE OF LEADERSHIP EFFECTS}

Transformational leadership has some very important positive effects for both organizations and individuals. The main issues include the following positive effects:

- high attachment and trust in leadership;

- the desire for submission to the leader;

- strong motivation and high performance;

- increasing group cohesion - shared beliefs amplification;

- low level of conflict - high degree of satisfaction;

- commitment towards achieving goals.

Leadership has the interpersonal relations in scope, working relations between the band leader - team, office, laboratory, etc.. - And he is subordinate staff. Leadership interpersonal relationships is done so through direct face to face, the head of the subordinates. The items above are considering by default, especially interpersonal leadership.

Besides these positive aspects, there are some potential negative effects. These include:

- Increased risk of addiction to lead subordinates;

- subordinates weakening of interpersonal relations;

- increased frequency of unconventional behavior;

- exacerbation of confidence;

- difficulties and even failures in planning.

It's actually in the classical leadership, which is confined almost entirely management specialists.

Symbiotic leadership style considered and future includes: • -examination by team performance criteria based on a participatory approach so as to ensure a fair distribution of 
organizational rewards relating to premiums, training and promotion;

-system builds motivation and improved communication, mutual trust, recognized as such by all components of the organization; - development of symbiotic team, the change in motivation increases the contribution of these groups, individual performance and the belief that those who have the most large contributions will be rewarded for it.

Leadership encourages symbiotic maximum contribution for each component of the organization. It develops a strong team spirit, based on strengthening individual identification with the group, the staff is motivated by positive expectations regarding a proper evaluation and reward.

The presence of full confidence levels catalyze the emergence of new, higher, output and productivity within the organization.

\section{EVALUATION MATHEMATICAL MODEL FOR LEADERSHIP}

\begin{tabular}{|l|l|c|}
\hline Variation levell & $\mathrm{x}$ & $\mathrm{y}$ \\
\hline Superior level $(+1)$ & 9 & 7,5 \\
\hline Basic level $(0)$ & 7 & 5 \\
\hline Inferior level $(-11)$ & 5 & 2,5 \\
\hline Variation interval $(\Delta \mathrm{xi})$ & 2 & 2,5 \\
\hline
\end{tabular}

Tab. 1. Variation levell

$\mathrm{X}$-oriented human resources

y-oriented work tasks

Coefficients are calculated $b_{0}, b_{1}, b_{12}$

b0 $=7,75$

b1 $=0,75$

b2 $=0,5$

b12 $=0$

\begin{tabular}{|c|c|c|c|c|c|}
\hline $\begin{array}{c}\text { Nr. } \\
\exp \end{array}$ & $\mathrm{x} 0$ & $\mathrm{x}$ & $\mathrm{y}$ & $\mathrm{xy}$ & $\mathrm{P}$ \\
\hline 1 & +1 & +1 & +1 & +1 & 9 \\
\hline 2 & +1 & -1 & +1 & -1 & 7,5 \\
\hline 3 & +1 & +1 & -1 & -1 & 8 \\
\hline 4 & +1 & -1 & -1 & +1 & 6,5 \\
\hline
\end{tabular}

Tab. 2. EFC matrix values

The matrix being orthogonal, coefficients b0, b1, b2, b12

$$
\mathrm{b}_{\mathrm{i}}=\frac{\sum_{\mathrm{u}=1}^{\mathrm{N}} \mathrm{x}_{\mathrm{i}_{\mathrm{u}}} \mathrm{y}_{\mathrm{u}}}{\sum_{\mathrm{u}=1}^{\mathrm{N}} \mathrm{x}_{\mathrm{i}_{\mathrm{u}}}^{2}}
$$

Mathematical model equation results for leadership style assessment

$$
P=4,2+0,35 x+0,2 y
$$

Successful leaders are rated by employees as being strongly oriented to tasks and relationships. Those achievements have these features. Strong orientation towards the tasks indicates that efforts are directed to activities that produce results, planning, assigning responsibilities and setting goals

Strong orientation toward establishing relations manager indicates that allows subordinates to influence the activities of work and is willing to allow the participation of subordinates in planning, setting goals and making decisions.

\section{CONCLUSION}

A very important role that plays in this process is that the evaluator must identify all persons involved or will be somehow affected by the assessment to be thought out ways to reduce negative influences on the assessment could have on them. People evaluating their employees should be perceived by those with maximum credibility, evaluators should be appreciated by those who will be assessed, this includes prestige evaluators and evaluative belief that the assessment made by them is correct and fair. Employee performance evaluation is a fundamental means by which managers and their subordinates can discuss issues in a systematic manner the work important.

A major problem is to increase leadership effectiveness particularly important in obtaining better results as the organizationAn important aspect of human resources management is represented by performance assessment within the organisation, because through evaluation we can better understand the dynamic nature of professional development.

Leadership approach on the basis of courtesy is likely to determine the organization's multidimensional performance gain. Leaders who achieve at high levels using a highly participatory management practices, are recognized as owners of developed interpersonal and communication described as open and willing to experiment with new ideas and concepts to subordinates, focusing on creating challenges and offering of greater responsibilities to subordinates. To motivate others, using low-achieving managers usually security issues.

Regarding evaluation, I would say that the evaluation of subordinates and the performance is part of the tasks of any manager. The reality is that when this assessment does not pay himself can properly guide and learn the responsibility of the employee.

A correct assessment and using efficient performance assessment methods can improve the accuracy of the data according to which employees are lead, and predictions are made in order to ensure human resources.

Successful leaders are rated by employees as being strongly oriented to tasks and relationships. Those achievements have these features. Strong orientation towards the tasks indicates that efforts are directed to activities that produce results, planning, assigning responsibilities and setting goals

For the success of the performance assessment activity I suggest the usage of certain mathematical models and computer programmes well conceived and easy to be implemented.

Contribution consists in developing a mathematical model that allows knowledge management style according to the factors of influence leadership.

Model variables can be organizational capacity, communication skills, sociability, intellectual potential and cognitive skills of working with people

\section{REFERENCES}

Burloiu, P. (1997). Human Resources Management, Published, ISBN 973-663-167-2, LUMINA LEX, Bucharest

Certo, C., S. (2001). Modern Management, Published, ISBN 973-95612-4-1, Teora, Bucharest

Cole G., A. (2000). Personnel Management, Published, ISBN: 973-8060-23-0, CODECS, Bucharest

Chişu, A., V. (2002). The Human Resources Specialist's Manual, Published, ISBN 973-20-0597-1, IRECSON, Bucharest

Pitariu, H., D. (2000). Human Resources Management Professional Performance Assessment, Published, ISBN 973-751-055-0, All Beck

Toader, R. (2004). Human Resources Management, Published, ISBN 973-656-895-4, Risoprint, Cluj - Napoca 